\section{JURNAL EKONOMI EFEKTIF}

ISSN : $2622-8882$, E-ISSN : 2622-9935

Jurnal Ekonomi Efektif, Vol. 4, No. 1, Oktober 2021 @Prodi Manajemen Fakultas Ekonomi Universitas Pamulang

\title{
PENGARUH KEPERCAYAAN DAN KEPUASAN PELANGGAN TERHADAP LOYALITAS KONSUMEN PADA TOKO ADELIA COLLECTION KOTA SORONG
}

\author{
Evi Mufrihah Zain ${ }^{1}$, Asmirayanti ${ }^{2}$, Retno Dewi Wijiastuti ${ }^{3 *}$ \\ Universitas Muhammadiyah, Sorong, Papua Barat, Indonesia \\ zevimufrihah@um-sorong.ac.id ${ }^{1}$, asmirayanti90@ gmail.com², \\ retnodewi@um-sorong.ac.id ${ }^{3 *}$
}

Manuskrip: Agustus -2021; Ditinjau: September: -2021; Diterima: September-2021; Online: Oktober-2021; Diterbitkan: Oktober-2021

\begin{abstract}
ABSTRAK
Penelitian ini telah menguji 2 variabel independen yaitu kepercayaan dan kepuasan pelanggan yang mempengaruhi variabel dependen yaitu loyalitas konsumen. tujuan penelitian ini adalah untuk mengetahui apakah variabel kepercayaan dan kepuasan pelanggan berpengaruh secara signifikan terhadap loyalitas konsumen. Metode penelitian ini menggunakan kuantitatif dengan pendekatan deskriptif korelasi menggunakan uji validitas, uji reliabilitas, uji asumsi klasik, uji regresi linear sederhana, uji regresi linear berganda, uji hipotesis (uji t) dan analisis koefisien determinasi (R2). Cara pengambilan sampel menggunakan metode purposive sampling dengan sampel yang diteliti sebanyak 60 responden. Metode statistik menggunakan anlisis regresi linear berganda dan uji t.hasil penelitian menunjukkan bahwa kepercayaan berpengaruh secara signifikan terhadap loyalitas konsumen dan kepuasan berpengaruh secara signifikan terhadap loyalitas konsumen.
\end{abstract}

\section{Kata Kunci: Kepercayaan, Kepuasan Pelanggan Dan Loyalitas Konsumen}

\begin{abstract}
This research has tested 2 independent variables, namely customer trust and satisfaction that affect the dependent variable, namely customer loyalty. the purpose of this study was to determine whether the variables of trust and customer satisfaction significantly influence consumer loyalty. In this research method using quantitative with descriptive correlation approach using validity test, reliability test, classic assumption test, simple linear regression test, multiple linear regression test, hypothesis test ( $t$ test) and analysis of the coefficient of determination (R2). How to take samples using a purposive sampling method with a sample of 60 respondents studied. The statistical method uses multiple linear regression analysis and $t$ test. The results of the study show that trust significantly influences customer loyalty and satisfaction significantly influences customer loyalty.
\end{abstract}

\section{Keywords: Trust, Customer Satisfaction and Consumer Loyalty}




\section{PENDAHULUAN}

Kebutuhan akan sandang merupakan kebutuhan primer setiap orang. Dari tahun ke tahun peningkatan produk sangatlah pesat. Dunia bisnis yang tumbuh dengan pesat menjadi tantangan maupun ancaman bagi para pelaku usaha agar dapat mempertahankan kelangsungan hidup perusahaannya.seiring dengan perkembangan jaman yang semakin maju, persaingan suatu bisnis menjadi kompetitif.dengan persaingan bisnis ini, para pelaku bisnis memiliki caranya dalam mengembangkan dan mempertahankan bisnisnya agar tetap bertahan. Salah satu bisnis yang saat ini sedang berkembang yaitu Toko Adelia Collection yang berada di Kota Sorong beralamat jl harapan indah km 11.5.

Menurut Oliver (1996:392) loyalitas konsumen adalah komitmen pelanggan bertahan secara mendalam untuk berlangganan kembali atau melakukan pembelian ulang produk/jasa terpilih secara konsisten dimasa yang akan datang,meskipun pengaruh situasi dan usaha-usaha pemasaran mempunyai potensi untuk menyebabkan perubahan perilaku.Sehingga dalam mempertahankan pelanggan perusahaan harus memperbaiki kinerja perusahaan dengan baik dengan meningkatkan loyalitas konsumen, perusahaan perlu memperhatikan faktor-faktor yang mempengaruhi menurut Zikmund dalam Venessa (2007) loyalitas konsumen dipengaruhi oleh lima faktor yaitu kepuasan,ikatan emosi, kepercayaan, kemudahan dan pengalaman dengan perusahaan.

Kepercayaan pelanggan merupakan hal yang ingin dimiliki oleh semua perusahaan dari para konsumen. Dengan adanya kerpercayaan konsumen maka akan terjadi pembelian ulang, mengajak orang lain untuk membeli produk yang dipercaya, menyebarkan citra positif produk yang dipercaya sehingga meningkatkan loyalitas. Menurut Kotler and Kevin (2007) kepuasan adalah perasaan senang atau kecewa seseorang yang muncul setelah membandingkan kinerja (hasil) produk yang di pikirkan terhadap kinerja (atau hasil) yang di harapkan..

Berdasarkan rumusan masalah yang di ambil dari faktor-faktor yang mempengaruhi loyalitas konsumen Toko Adelia Collection maka peneliti menggunakan uji analisis regresi linier sederhana dan analisis regresi berganda. Maka dari itu peneliti mengangkat judul "Pengaruh Kepercayaan Dan Kepuasan Pelanggan Terhadap Loyalitas Konsumen Pada Toko Adelia Collection Kota Sorong',

\section{METODE PENELITIAN}

Metode yang digunakan dalam penelitian ini adalah metode kuantitatif dengan menggunakan pendekatan deskriptif korelasi. Lokasi penelitian adalah pada Toko Adelia Collection yang beralamat dijalan harapan indah $\mathrm{Km} \mathrm{11,5}$. Objek penelitian yang akan diteliti adalah kepercayaaan, kepuasaan pelanggan dan loyalitas konsumen. Populasi penelitian mengacu pada pelanggan Toko Adelia Collection Kota sorong dan sampel penelitian adalah 60 responden yang menjadi pelanggan tetap Toko Adelia Collection Kota Sorong. Teknik pengambilan data yang saya gunakan dalam penelitian adalah menggunakan Teknik purposive sampling, Jenis data dalam penelitian adalah penelitian kuantitatif dan Sumber data peneliti ada dua bagian yaitu Primer dan Sekunder dan Metode yang digunakan oleh peneliti adalah kuesioner, wawancara dan studi pustaka.

\section{HASIL PENELITIAN}

\section{Uji Regresi Sederhana}

Penelitian ini menggunakan regresi linear sederhana untuk pembuktian hipotesis pertama penelitian ini Variabel $\left(\mathrm{X}_{1}\right)$ Kepercayaan Terhadap Loyalitas konsumen (Y). Analisis ini akan menggunakan input berdasarkan data yang diperoleh dari kuesioner 
Tabel 1 Uji Regresi Linear Sederhana (X1) Coefficients ${ }^{\mathrm{a}}$

\begin{tabular}{|ll|r|r|r|r|r|}
\hline \multirow{2}{*}{ Model } & \multicolumn{2}{|l|}{ Unstandardized Coefficients } & $\begin{array}{l}\text { Standardized } \\
\text { Coefficients }\end{array}$ & \multicolumn{1}{c|}{ T } & \multirow{2}{*}{ Sig. } \\
\cline { 2 - 5 } & \multicolumn{1}{|c|}{ B } & Std. Error & \multicolumn{1}{c|}{ Beta } & & \\
\hline \multirow{2}{*}{1} & (Constant) & 4.782 & 5.295 & & .903 & .370 \\
Kepercayaan & .861 & .084 & .804 & 10.304 & .000 \\
\hline
\end{tabular}

a. Dependent Variable: Loyalitas Konsumen

Sumber : Lampiran output SPSS 20, 2019

Tabel 2 Uji Regresi Linear Sederhana (X2)

Coefficients ${ }^{\mathrm{a}}$

\begin{tabular}{|c|c|c|c|c|c|}
\hline \multirow[t]{2}{*}{ Model } & \multicolumn{2}{|c|}{ Unstandardized Coefficients } & \multirow{2}{*}{$\begin{array}{c}\begin{array}{c}\text { Standardized } \\
\text { Coefficients }\end{array} \\
\text { Beta }\end{array}$} & \multirow[t]{2}{*}{$\mathrm{T}$} & \multirow[t]{2}{*}{ Sig. } \\
\hline & $\mathrm{B}$ & Std. Error & & & \\
\hline \multirow{2}{*}{$\begin{array}{ll}1 & \text { (Constant) } \\
\text { Kepuasan Pelanggan }\end{array}$} & 2.935 & 4.624 & & .635 & .528 \\
\hline & .922 & .076 & .848 & & .000 \\
\hline
\end{tabular}

a. Dependent Variable: Loyalitas Konsumen

Hasil analisis regresi linear sederhana yang masih berbentuk angka hipotesis pertama dengan variabel kepercayaan (X1) terhadap loyalitas konsumen (Y) dengan hasil $\mathrm{Y}=4,782+0,861 \mathrm{X}_{1}$. Analisis regresi sederhana hipotesis kedua dengan variabel kepuasan pelanggan (X2) terhadap loyalitas konsumen $(\mathrm{Y})$ dengan hasil $\mathrm{Y}=2,935+$ $0,922 \mathrm{X}_{2}$

\section{Analisis Regresi Linear Berganda}

Penelitian ini menggunakan regresi linear berganda untuk pembuktian hipotesis penelitian. Analisis ini akan menggunakan input berdasarkan data yang diperoleh dari kuesioner.

Tabel 3 Analisis Regresi Linear Berganda

\begin{tabular}{|c|c|c|c|c|c|}
\hline \multirow[t]{2}{*}{ Model } & \multicolumn{2}{|c|}{$\begin{array}{c}\text { Unstandardized } \\
\text { Coefficients }\end{array}$} & $\begin{array}{l}\text { Standardized } \\
\text { Coefficients }\end{array}$ & \multirow[t]{2}{*}{$\mathrm{T}$} & \multirow[t]{2}{*}{ Sig. } \\
\hline & $\mathrm{B}$ & Std. Error & Beta & & \\
\hline \multirow{3}{*}{$\begin{array}{l}\text { (Constant) } \\
\text { Kepercayaan } \\
\text { Kepuasan Pelanggan }\end{array}$} & -1.832 & 4.583 & & -.400 & .691 \\
\hline & .365 & .118 & .341 & 3.092 & .003 \\
\hline & .622 & .120 & .572 & 5.187 & .000 \\
\hline
\end{tabular}

Sumber : lampiran output SPSS 20, 2019

Untuk mengetahui pengaruh variabel kepercayaan (X1) dan kepuasan pelanggan (X2), terhadap loyalitas konsumen (Y), maka digunakan analisi regresi berganda. Dengan hasil persamaan regresi yang masih berbentuk angka $Y=-1,832+0,365 \mathrm{X}_{1}+$ $0,622 \mathrm{X}_{2}$.

\section{Uji validitas}

Uji validitas digunakan untuk mengukur sah atau valid tidaknya suatu kuesioner, suatu kuesioner dikatakan valid jika pertanyaan pada kuesioner mampu untuk mengungkapkan sesuatu yang diukur oleh kuesioner tesebut (Ghozali,2006). Uraian hasil pengujian validitas instrumen disajikan dalam tebel sebagai berikut : 
Tabel 4 Uji Validitas

\begin{tabular}{|c|c|c|c|c|c|}
\hline No & Variabel & Item & $\mathbf{r}$ hitung & $r$ tabel & Keterangan \\
\hline \multirow{15}{*}{1} & \multirow{15}{*}{ KEPERCAYAAN } & $\mathrm{X} 1-1$ & $.601 * *$ & 0.2542 & Valid \\
\hline & & $\mathrm{X} 1-2$ & $.602 * *$ & 0.2542 & Valid \\
\hline & & $\mathrm{X} 1-3$ & $.440 * *$ & 0.2542 & Valid \\
\hline & & $\mathrm{X} 1-4$ & $.743 * *$ & 0.2542 & Valid \\
\hline & & $\mathrm{X} 1-5$ & $.574 * *$ & 0.2542 & Valid \\
\hline & & $\mathrm{X} 1-6$ & $.468 * *$ & 0.2542 & Valid \\
\hline & & $\mathrm{X} 1-7$ & $.446 * *$ & 0.2542 & Valid \\
\hline & & $\mathrm{X} 1-8$ & $.633 * *$ & 0.2542 & Valid \\
\hline & & X1-9 & $.530 * *$ & 0.2542 & Valid \\
\hline & & $\mathrm{X} 1-10$ & $.635 * *$ & 0.2542 & Valid \\
\hline & & $\mathrm{X} 1-11$ & $.725 * *$ & 0.2542 & Valid \\
\hline & & $\mathrm{X} 1-12$ & $.738 * *$ & 0.2542 & Valid \\
\hline & & $\mathrm{X} 1-13$ & $.527 * *$ & 0.2542 & Valid \\
\hline & & $\mathrm{X} 1-14$ & $.732 * *$ & 0.2542 & Valid \\
\hline & & $\mathrm{X} 1-15$ & $.716^{* *}$ & 0.2542 & Valid \\
\hline \multirow{15}{*}{2} & \multirow{15}{*}{$\begin{array}{l}\text { KEPUASAN } \\
\text { PELANGGAN }\end{array}$} & $\mathrm{X} 2-1$ & $.551 * *$ & 0.2542 & Valid \\
\hline & & $\mathrm{X} 2-2$ & $.617 * *$ & 0.2542 & Valid \\
\hline & & $\mathrm{X} 2-3$ & $.586 * *$ & 0.2542 & Valid \\
\hline & & $\mathrm{X} 2-4$ & $.625 * *$ & 0.2542 & Valid \\
\hline & & $\mathrm{X} 2-5$ & $.592 * *$ & 0.2542 & Valid \\
\hline & & $X 2-6$ & $.459 * *$ & 0.2542 & Valid \\
\hline & & $\mathrm{X} 2-7$ & $.685 * *$ & 0.2542 & Valid \\
\hline & & X2-8 & $.692 * *$ & 0.2542 & Valid \\
\hline & & X2-9 & $.592 * *$ & 0.2542 & Valid \\
\hline & & $\mathrm{X} 2-10$ & $.616^{* *}$ & 0.2542 & Valid \\
\hline & & $\mathrm{X} 2-11$ & $.596 * *$ & 0.2542 & Valid \\
\hline & & $\mathrm{X} 2-12$ & $.651 * *$ & 0.2542 & Valid \\
\hline & & $\mathrm{X} 2-13$ & $.619 * *$ & 0.2542 & Valid \\
\hline & & $\mathrm{X} 2-14$ & $.625^{* *}$ & 0.2542 & Valid \\
\hline & & $\mathrm{X} 2-15$ & $.639 * *$ & 0.2542 & Valid \\
\hline \multirow{15}{*}{3} & \multirow{15}{*}{$\begin{array}{l}\text { LOYALITAS } \\
\text { KONSUMEN }\end{array}$} & $\mathrm{Y}-1$ & $.656 * *$ & 0.2542 & Valid \\
\hline & & $\mathrm{Y}-2$ & $.742 * *$ & 0.2542 & Valid \\
\hline & & $\mathrm{Y}-3$ & $.667 * *$ & 0.2542 & Valid \\
\hline & & $\mathrm{Y}-4$ & $.635^{* *}$ & 0.2542 & Valid \\
\hline & & Y-5 & $.783 * *$ & 0.2542 & Valid \\
\hline & & Y-6 & $.638 * *$ & 0.2542 & Valid \\
\hline & & $\mathrm{Y}-7$ & $.690 * *$ & 0.2542 & Valid \\
\hline & & Y-8 & $.620 * *$ & 0.2542 & Valid \\
\hline & & Y-9 & $.602 * *$ & 0.2542 & Valid \\
\hline & & $\mathrm{Y}-10$ & $.543 * *$ & 0.2542 & Valid \\
\hline & & Y-11 & $.691 * *$ & 0.2542 & Valid \\
\hline & & $\mathrm{Y}-12$ & $.574 * *$ & 0.2542 & Valid \\
\hline & & $Y-13$ & $.776 * *$ & 0.2542 & Valid \\
\hline & & $Y-14$ & $.675 * *$ & 0.2542 & Valid \\
\hline & & $Y-15$ & $.633 * *$ & 0.2542 & Valid \\
\hline
\end{tabular}

Sumber :Data lampiran output SPSS 20,2019

diatas menunjukkan bahwa seluruh item pertanyaan memiliki corrected itemcorrelation $r$ hitung $>$ dari $r$ tabel yaitu 0.2542 . ini berarti seluruh item masing-masing yang ada dinyatakan valid. 


\section{Uji Reliabilitas}

Alat ukur yang akan digunakan adalah Croanbach Alpha melalui program SPSS 20. Reliabilitas suatu konstruk variabel dikatakan baik jika memiliki nilai Croanbach Alpha> 0.60 .

Tabel 5 Uji Reliabilitas Variabel

\begin{tabular}{|c|c|c|}
\hline Variabel & Cronbach's Alpha & Keterangan \\
\hline Kepercayaan & 0.907 & Reliabel \\
\hline kepuasan pelanggan & 0.900 & Reliabel \\
\hline Loyalitas Konsumen & 0.925 & Reliabel \\
\hline \multicolumn{2}{|c|}{ Sumber: Data Primer diolah, 2019}
\end{tabular}

Berdasarkan Tabel diatas menunjukkan bahwa semua variabel mempunyai Cronbach Alpha yang cukup besar yaitu di atas 0,60 sehingga dapat dikatakan semua konsep pengukur masing-masing variabel dari kuesioner adalah reliabel sehingga untuk selanjutnya item-item pada masing-masing konsep variabel tersebut layak digunakan sebagai alat ukur.

\section{Uji Asumsi Klasik}

\section{a. Uji Normalitas}

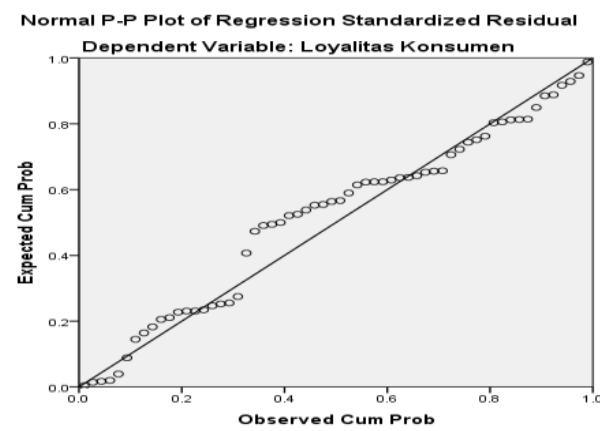

Gambar 1 Uji Normalitas

Sumber : lampiran output SPSS 20, 2019

Uji normalitas bertujuan untuk menguji apakah dalam model regresi, variabel terikat, variabel bebas atau keduanya mempunyai distribusi normal atau tidak. hasil bahwa semua data berdistribusi secara normal. Karena, menyebar, data berada disekitar garis diagonal, jadi model regresi memenuhi asumsi normalits.

\section{b. Uji Linearitas}

Uji linearitas bertujuan untuk mengetahui apakah dua variabel mempunyai hubungan yang linear atau tidak secara signifikan

Tabel 6 Uji linearitas Kepercayaan terhadap Loyalitas Konsumen

\section{ANOVA Table}

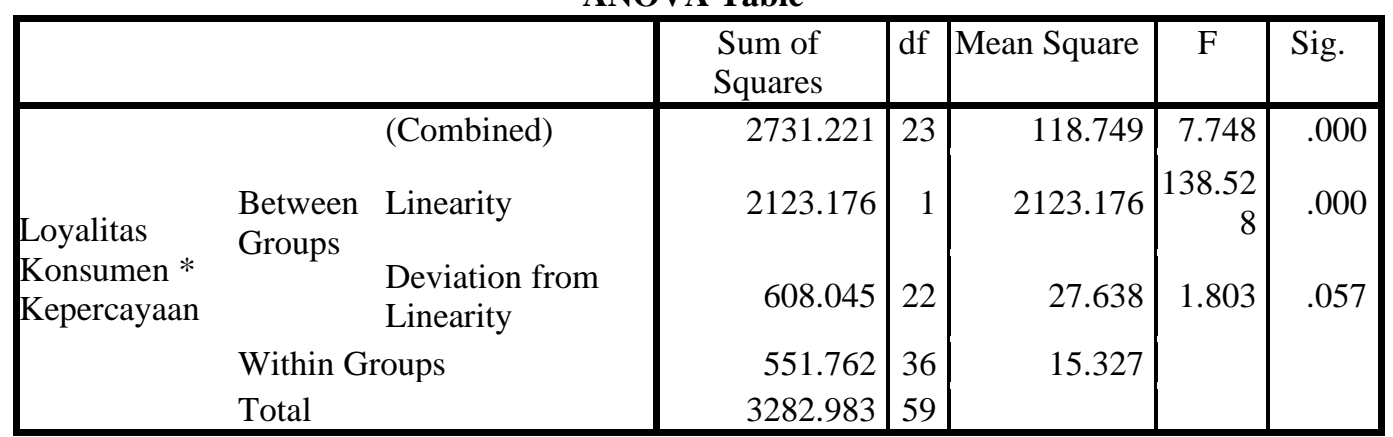


Tabel 7 Uji Linearitas Kepuasaan Terhadap Loyalitas konsumen

\begin{tabular}{|c|c|c|c|c|c|c|c|}
\hline & & & $\begin{array}{l}\text { Sum of } \\
\text { Squares }\end{array}$ & $\mathrm{df}$ & $\begin{array}{c}\text { Mean } \\
\text { Square }\end{array}$ & $\mathrm{F}$ & Sig. \\
\hline \multirow{6}{*}{$\begin{array}{l}\text { Loyalitas } \\
\text { Konsumen * } \\
\text { Kepuasan } \\
\text { Pelanggan }\end{array}$} & & (Combined) & 2611.133 & 23 & 113.528 & 6.083 & .000 \\
\hline & Between & Linearity & 2362.962 & 1 & 2362.962 & 126.616 & .000 \\
\hline & Groups & Deviation from & 248171 & 22 & 11280 & \multirow{4}{*}{.604} & \multirow{4}{*}{.893} \\
\hline & & Linearity & $240.1 / 1$ & & & & \\
\hline & \multicolumn{2}{|c|}{ Within Groups } & 671.850 & 36 & 18.662 & & \\
\hline & \multicolumn{2}{|l|}{ Total } & 3282.983 & 59 & & & \\
\hline
\end{tabular}

Sumber : lampiran Output SPSS, 2019

nilai uji variabel kepercayaan (X1) signifikansi (linearity) 0,000 dan variabel kepuasan pelanggan (X2) signifikansi (linearity) 0,000 dengan dasar pengambilan keputusan dua variabel dikatakan mempunyai hubungan yang linear bila signifikansi (linearity) kurang dari 0,05. Maka disimpulkan uji linearitas mempunyai hubungan yang linear.

\section{c. Uji Multikolinearitas}

Uji multikolinearitas bertujuan untuk menguji apakah dalam model regresi ditemukan adanya korelasi antar variabel-variabel bebas (ghozali,2006).

Tabel 8 Hasil Uji Multikolinieritas

\begin{tabular}{|ll|r|r|}
\hline \multirow{2}{*}{ Model } & \multicolumn{2}{|c|}{ Collinearity Statistics } \\
\cline { 2 - 3 } & Tolerance & \multicolumn{1}{|c|}{ VIF } \\
\hline \multirow{2}{*}{1 (Constant) } & & \\
1 & Kepercayaan & .346 & 2.892 \\
\cline { 2 - 3 } & Kepuasan Pelanggan & .346 & 2.892 \\
\hline
\end{tabular}

Sumber : lampiran output SPSS 20,2019

Uji multikolinieritas bertujuan untuk menguji apakah pada model regresi ditemukan adanya korelasi antar variabel bebas atau variabel independent. Berdasarkan hasil penelitian dapat diketahui bahwa nilai VIF adalah : 2,892 untuk variabel kepercayaan (X1) dan 2,892 untuk variabel Kepuasan Pelanggan (X2). Hasil ini berarti variabel bebas dari asumsi klasik multikolinieritas, karena hasilnya kurang dari 10. Begitu juga dengan nilai tolerance semuanya diatas 0,1 .

\section{d. Uji Heteroskedastisitas}

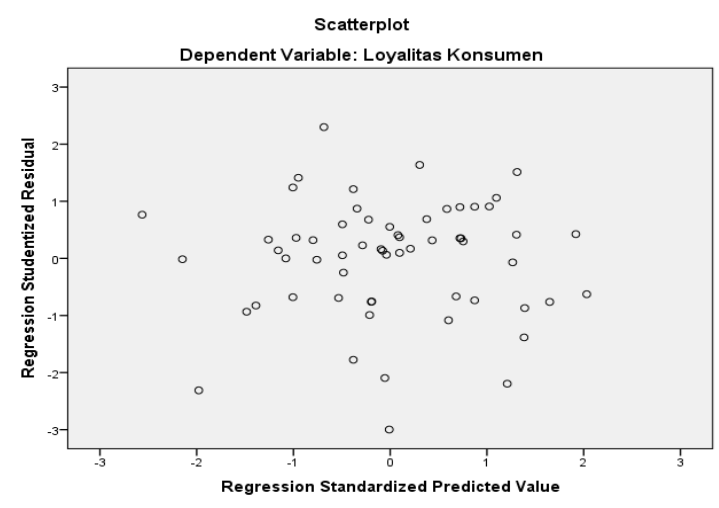

Gambar 2.Hasil Uji Heteroskedastisitas Sumber : lampiran output SPSS 20, 2019

Model regresi yang baik adalah tidak terjadi Heteroskedastisitas. Berdasarkan gambar 2 diatas menunjukkan bahwa dari grafik Scatterplot tersebut terlihat titiktitik yang menyebar secara acak, tidak membentuk suatu pola tertentu yang jelas, serta tersebar baik di atau maupun di bawah angka 0 (nol) pada sumbu Y, hal ini 
berarti tidak terjadi penyimpangan asumsi klasik heteroskedastisitas pada model regresi yang dibuat.

\section{Uji t (Parsial)}

Uji t menunjukkan seberapa jauh pengaruh satu variabel independen secara parsial dalam menerangkan variasi variabel dependen.

Tabel 9 Analisis Uji t kepercayaan terhadap loyalitas konsumen

\section{Coefficients $^{\text {a }}$}

\begin{tabular}{|c|c|c|c|c|c|c|c|c|c|c|}
\hline \multirow[t]{2}{*}{ Model } & \multicolumn{2}{|c|}{$\begin{array}{l}\text { Unstandardiz } \\
\text { ed } \\
\text { Coefficients }\end{array}$} & \multirow{2}{*}{\begin{tabular}{|c}
$\begin{array}{c}\text { Standardi } \\
\text { zed } \\
\text { Coefficie } \\
\text { nts }\end{array}$ \\
Beta
\end{tabular}} & \multirow[t]{2}{*}{$\mathrm{T}$} & \multirow[t]{2}{*}{ Sig. } & \multicolumn{3}{|c|}{ Correlations } & \multicolumn{2}{|c|}{$\begin{array}{c}\text { Collinearity } \\
\text { Statistics }\end{array}$} \\
\hline & B & $\begin{array}{l}\text { Std. } \\
\text { Error }\end{array}$ & & & & $\begin{array}{l}\text { Zero- } \\
\text { order }\end{array}$ & $\begin{array}{c}\text { Partia } \\
1\end{array}$ & Part & $\begin{array}{c}\text { Tolera } \\
\text { nce }\end{array}$ & VIF \\
\hline (Constant) & 4.782 & 5.295 & & .903 & .370 & & & & & \\
\hline Kepercayaan & .861 & .084 & .804 & $\begin{array}{r}10.30 \\
4\end{array}$ & .000 & .804 & .804 & .804 & 1.000 & 1.000 \\
\hline
\end{tabular}

a. Dependent Variable: Loyalitas Konsumen

Uji $t$ bertujuan untuk mengetahui ada tidaknya pengaruh parsial yang diberikan variabel bebas $(\mathrm{X})$ terhadap variabel terikat $(\mathrm{Y})$. Berdasarkan hasil penghitungan uji pertama $\mathrm{t}_{\text {tabel }}=(\alpha / 2: \mathrm{n}-\mathrm{k}-1)$ maka Diketahui nilai t Hitung 13,304 $>\mathrm{t}$ tabel 2,002 dan nilai sig untuk pengaruh Kepuasan Pelanggan (X2) terhadap loyalitas konsumen (Y) adalah sebesar $0.000<0.05$ sehingga dapat disimpulkan bahwa $\mathrm{H} 0$ ditolak dan $\mathrm{H} 1$ diterima yang artinya kepercayaan (X2) berpengaruh positif dan signifikan terhadap loyalitas konsumen(Y).

Tabel 10 Analisis Uji t kepuasan pelanggan terhadaap loyalitas konsumen

\section{Coefficients $^{\mathrm{a}}$}

\begin{tabular}{|c|c|c|c|c|c|c|c|c|c|c|}
\hline \multirow[t]{2}{*}{ Model } & \multicolumn{2}{|c|}{$\begin{array}{l}\text { Unstandardized } \\
\text { Coefficients }\end{array}$} & \multirow{2}{*}{\begin{tabular}{|c}
$\begin{array}{c}\text { Standard } \\
\text { ized } \\
\text { Coeffici } \\
\text { ents }\end{array}$ \\
Beta
\end{tabular}} & \multirow[t]{2}{*}{$\mathrm{T}$} & \multirow[t]{2}{*}{ Sig. } & \multicolumn{3}{|c|}{ Correlations } & \multicolumn{2}{|c|}{$\begin{array}{l}\text { Collinearity } \\
\text { Statistics }\end{array}$} \\
\hline & B & $\begin{array}{l}\text { Std. } \\
\text { Error }\end{array}$ & & & & $\begin{array}{l}\text { Zero- } \\
\text { order }\end{array}$ & $\begin{array}{c}\text { Partia } \\
1\end{array}$ & Part & $\begin{array}{c}\text { Tolera } \\
\text { nce }\end{array}$ & VIF \\
\hline (Constant) & 2.935 & 4.624 & & .635 & .528 & & & & & \\
\hline $1 \begin{array}{l}\text { Kepuasan } \\
\text { Pelanggan }\end{array}$ & .922 & .076 & .848 & $\begin{array}{r}12.20 \\
5\end{array}$ & .000 & .848 & .848 & .848 & 1.000 & 1.000 \\
\hline
\end{tabular}

a. Dependent Variable: Loyalitas Konsumen

Sumber : lampiran output SPSS 20, 2019

Uji t bertujuan untuk mengetahui ada tidaknya pengaruh parsial yang diberikan variabel bebas $(\mathrm{X})$ terhadap variabel terikat $(\mathrm{Y})$. Berdasarkan hasil penghitungan uji pertama $t_{\text {tabel }}=(\alpha / 2: \mathrm{n}-\mathrm{k}-1)$. Maka Diketahui nilai t Hitung 12,205 $>\mathrm{t}$ tabel 2,002 dan nilai sig untuk pengaruh Kepuasan Pelanggan (X2) terhadap loyalitas konsumen (Y) adalah sebesar $0.000<0.05$ sehingga dapat disimpulkan bahwa $\mathrm{H} 0$ ditolak dan $\mathrm{H} 2$ diterima yang artinya kepuasan pelanggan (X2) berpengaruh positif dan signifikan terhadap loyalitas konsumen(Y)

\section{Koefisiensi Determinasi}

Koefisien determinasi ini digunakan untuk mengetahui seberapa besarnya persentase hubungan variabel independen terhadap variabel dependen. dapat dilihat dari besarnya nilai R Squrare. 
Tabel 11 Analisis Koefisien Determinasi $\left(\mathrm{R}^{2}\right)$ Model Summary ${ }^{\mathbf{b}}$

\begin{tabular}{|c|c|c|c|c|c|c|c|c|c|}
\hline \multirow[t]{2}{*}{ Model } & \multirow[t]{2}{*}{$\mathrm{R}$} & \multirow{2}{*}{$\begin{array}{l}\text { R } \\
\text { Squar } \\
\text { e }\end{array}$} & \multirow{2}{*}{$\begin{array}{l}\text { Adjusted } \\
\text { R Square }\end{array}$} & \multirow{2}{*}{$\begin{array}{l}\text { Std. Error } \\
\text { of the } \\
\text { Estimate }\end{array}$} & \multicolumn{5}{|c|}{ Change Statistics } \\
\hline & & & & & $\begin{array}{l}\text { R Square } \\
\text { Change }\end{array}$ & $\begin{array}{c}\mathrm{F} \\
\text { Change }\end{array}$ & df1 & df2 & $\begin{array}{c}\text { Sig. F } \\
\text { Change }\end{array}$ \\
\hline 1 & $.872^{\mathrm{a}}$ & .760 & .752 & 3.718 & .760 & 90.254 & 2 & 57 & .000 \\
\hline
\end{tabular}

a. Predictors: (Constant), Kepuasan Pelanggan, Kepercayaan

b. Dependent Variable: Loyalitas Konsumen

Sumber : lampiran output SPSS versi 202019

diketahui $\mathrm{R}$ Square sebesar 0.752, hal ini menggandung arti bahwa pengaruh Variabel Kepercayaan (X1) dan Kepuasan Pelanggan (X2) secara silmultan terhadap variabel Loyalitas Konsumen (Y) sebesar 75,2\%. Dimana $100-75,2 \%=24,8 \%$ sehingga Sisanya 24,8 \% Dapat Dijelaskan Oleh Variabel Lain Diluar Dari Variabel Penelitian

\section{Pembahasan}

a. Pengaruh Kepercayaan terhadap loyalitas Konsumen

Hasil penelitian ini mendukung hipotesis pertama yang menyatakan bahwa terdapat pengaruh positif kepercayaan terhadap Loyalitas Konsumen Pada Toko Adelia Collection Kota Sorong.Pengujian hipotesis pertama menghasilkan nilai koefisien regresi sebesar 0.861. Hal tersebut menunjukkan bahwa apabila nilai Kepercayaan (X1) mengalami peningkatan sebesar 1 satuan, maka nilai Loyalitas Konsumen Pada Toko Adelia Collection Kota Sorong akan meningkat sebesar 0.861 satuan. Variabel Kepercayaan memiliki thitung sebesar 10,304 dimana lebih besar dari pada nilai t tabel yaitu sebesar 2,002 dengan nilai signifikansi sebesar 0,000 lebih kecil dari pada 0,05. Sesuai dengan uraian tersebut dapat disimpulkan bahwa Kepercayaan berpengaruh terhadap Loyalitas konsumen Pada Toko adelia Collection Kota sorong . sehingga hipotesis pertama yang menyatakan terdapat pengaruh positif Kepercayaan terhadap Loyalitas Konsumen Pada Toko adelia Collection Kota Sorong Diterima. Maka hasil penelitian ini sejalan dengan hasil penelitian dari Neny Kusumadewi (2017) yang menyatakan bahwa Kepuasan pelanggam memiliki pengaruh terhadap loyalitas konsumen.

b. Pengaruh Kepuasan Pelanggan terhadap Loyalitas Konsumen

Hasil penelitian ini mendukung hipotesis kedua yang menyatakan bahwa terdapat pengaruh positif kepuasan pelanggan terhadap loyalitas Konsumen Pada Toko Adelia Collection Kota Sorong. Pengujian hipotesis kedua menghasilkan nilai koefisien regresi sebesar 0.922 . Hal tersebut menunjukkan bahwa apabila nilai kepuasan pelanggan (X2) mengalami peningkatan sebesar 1 satuan, maka nilai Loyalitas Konsumen Pada Toko Adelia Collection Kota Sorong akan meningkata sebesar 0.922 satuan.Variabel Kepuasan Pelanggan memiliki t hitung sebesar 12,205 dimana lebih besar dari pada nilai t tabel yaitu sebesar 2,002 dengan nilai signifikansi sebesar 0,000 lebih kecil dari pada 0,05. Sesuai dengan uraian tersebut dapat disimpulkan bahwa kepuasan Pelanggan berpengaruh terhadap Loyalitas Konsumen Pada Toko Adelia Collection Kota Sorong. Sehingga hipotesis kedua yang menyatakan terdapat pengaruh kepuasan Pelanggan berpengaruh terhadap Loyalitas Konsumen Pada Toko Adelia Collection Kota Sorong Diterima. Maka hasil penelitian ini sejalan dengan hasil penelitian dari Putri farrah andini (2013) yang menyatakan bahwa Kepuasan pelanggam memiliki pengaruh terhadap loyalitas konsumen. 


\section{KESIMPULAN}

Berdasarkan hasil penelitian dan pembahasan, maka dapat ditarik beberapa kesimpulan sebagai berikut:

1. Kepercayaan berpengaruh positif dan Signifikan terhadap loyalitas Konsumen Pada Toko Adelia Collection Kota Sorong. Hal ini dibuktikan dengan terjawabnya hipotesis, dimana hipotesis kepercayaan $(\mathrm{X} 1)=10.304$ lebih besar dari t tabel 2,002 dengan sig.= $0,000<0,05$.

2. Kepuasan pelanggan berpengaruh positif dan Signifikan terhadap loyalitas Konsumen pada Toko Adelia Collection Kota Sorong. Hal ini dibuktikan dengan terjawabnya hipotesis, dimana hipotesis kepuasan pelanggan $(\mathrm{X} 2)=12.205$ lebih besar dari t tabel 2,002 dengan sig. $=0,000<0,05$.

3. Hasil nilai koefisien determinasi kepercayaan (X1) dan kepuasan pelanggan (X2) berpengaruh terhadap loyalitas konsumen (Y) sebesar 0,752 atau 75,2\% yang artinya $24,8 \%$ sisanya dipengaruhi oleh variabel lain.

\section{DAFTAR PUSTAKA}

Andini, Putri Farrah, 2013. Analisis Pengaruh Suasana Toko, Kualitas produk, Kepuasaan Pelanggan Terhadap Loyalitas Pelangga Studi Pada Konsumen Distro Deep Di Surakarta.Jurnal Penelitian.

Barnes, 2003. Secrets Of Customer Relationship Management. Andi :Yogyakarta

Fitri, Ista. 2016. Pengaruh Kepercayaan, Lokasi Dan Brand Image terhadap Loyalitas Konsumen Pengguna Jasa Kiriman Barang pada JNE EXPRESS Cabang Padang Aro. Jurnal Penelitian.

Gaffar, Vanessa, 2007. Cortumer relationship management and Marketing Publik Relation Bandung : Alfabeta

Griffin, 2010. Customer Loyalty : menumbuhkan dan Mempertahankan Kesetiaan pelangga. Erlangga: Jakarta.

Hurriyati, ratih, 2010.Bauran pemasaran Dan Loyalitas Konsumen. Bandung:Alfabeta,cv.

Kotler, Philip and Kevin Lane Keller, 2007. Manajemen Pemasaran, Jilid 12, Jakarta : PT Indeks.

Kotler, Philip dan Keller, Lane Kevin. (2009). Manajemen Pemasaran Edisi 13 Jilid 1. Erlangga: Jakarta

Kusumadewi, Neny.2017. Pengaruh Kualitas Pelayanan dan Kepercayaan Terhadap Loyalitas Pelanggan Pada Toko UD. PUTRA TS Majalengka, Majalengka: jurnal Penelitian.

Maddinsyah, A., et al. (2020). Desain Formulasi Dan Implementasi Bisnis Strategik Dengan Pendekatan Business Model Canvas (BMC) Terintegrasi Kerangka Integrated Performance Management System (IPMS) Pada Koperasi Asperindo. Inovasi, 7(2), 67-76.

Oliver, 2010. Ratih hurriyati Dalam Buku Bauran pemasaran Dan loyalitas Konsumen. Bandung:Alfabeta,cv.

Rofianto, W., et al. (2021). Cultural Product Branding, Antecedents, And Its Implications: A Study On The Context Of Indonesian Batik. International Journal Of Social, Policy And Law, 2(2), 37-46.

Sugiyono. 2006. Metode penelitian kuantitatif, kualitatif dan $R \& D$, Bandung : Alfabeta. Sugiyono. 2019. Metode Penelitian Kuantitatif, kualitatif dan $R \& D$, Bandung : Alfabeta. Wangsi, M. M., et al. (2018). Perlindungan Konsumen Dalam Pelabelan Produk Menurut Ekonomi Islam. Sentralisasi, 7(1), 1-9. 